\title{
Ars Moda - Moda, Design, Arte e Técnica
} Ars Moda - Fashion, Design, Art and Technique

\section{MARTINS, Leilane Rigatto I Mestre em Arquitetura e Urbanismo}

Universidade de São Paulo

lanerigatto@gmail.com

\section{MARTINS, Sérgio Régis Moreira I Professor Dr. e Livre Do-} cente da Faculdade de Arquitetura e Urbanismo

Universidade de São Paulo

sergiore@usp.br

\section{Resumo}

O propósito deste artigo é discutir brevemente a relação entre moda, design e arte, mantendo a distinção essencial entre as áreas. Passando pelos conceitos de arte, técnica e design o texto busca estabelecer relações entre as áreas design e arte e moda e arte - em uma dinâmica interdisciplinar, híbrida, que levanta questões do período moderno e contemporâneo.

Palavras-chave: Moda. Design. Arte. Modernidade.

\section{Abstract}

The purpose of this article is to discuss briefly the relationship between fashion, design and art, manteining the essential distinction between the areas. Defining art, design and technical the text seeks to establish relationships between the three areas - fashion, design and art - in a dynamic interdisciplinary, hybrid, that raises questions of modern and contemporary times.

KeyWords: Fashion. Design. Art. Modernity. 


\section{INTRODUC̣̃̃O}

Muito se discute sobre a união ou separação total entre design e arte. Mesmo que sejam reconhecidos estatutos diferentes para esses dois campos da produção visual, cada vez mais eles convergem para uma hibridização. No caso da moda esse contato com a arte é facilitado pela porosidade que ela oferece. Essa porosidade entre as áreas nem sempre permite enxergar onde acaba uma e onde começa outra.

Essa condição existe no design de produtos, no design gráfico, no design de maneira geral, mas é mais marcante no design de moda.

O presente artigo, que foca no design de moda, entende que este é uma extensão do termo design, que constitui um campo maior, o qual compreende o design de produtos, de interiores etc. Muitas vezes será usada a expressão design que servirá aqui para se referir também ao design de moda, sem excluir o design em sua acepção mais generalista dessa dinâmica.

Buscando estabelecer uma relação possível entre arte, design e design de moda, o presente artigo levanta algumas questões pertinentes ao momento atual que trazem à tona a discussão da divisão estanque entre design e arte que vigorou até meados do século XX.

A complexidade do termo design se estende até seu étimo. Essa palavra inglesa tem origem no latim. Sinônimo mundial da pesquisa, criação e desenvolvimento de interfaces concebidas para facilitar o cotidiano das pessoas, o design surgiu segundo Ferrara (2011, p. 68) "como um desafio para uma sociedade pós-industrial que precisa reinventar o valor de troca e redescobrir sua dimensão", enquanto o desenho industrial "se define como índice legítimo da ideologia modernista do século XIX ou [ainda] no auge de seu sistema produtivo, como um dos expoentes de uma sociedade de consumo" (FERRARA, 2011, p. 68).

Destacadas as diferenças entre ambas as expressões, o termo design consagra em sua amplitude a atividade anteriormente chamada de desenho industrial.

O alcance do substantivo design em países de outras línguas que não o inglês serve para reforçar a unificação de um ideal universal. Dessa forma é enfatizado o enraizamento de uma cultura ligada ao design, tanto na língua quanto ao ato criativo de conceber produtos em culturas diversas.

O uso maciço que passou a se fazer do termo design no século $X X$, mostra 
como a língua inglesa unificou este ideal universal. A partir daí é possível fazer uma analogia entre o alcance do inglês e do design no mundo a partir da conveniência de se definir um termo comum para essa atividade.

Este ideal universal foi alcançado não só pelo emprego do étimo design em épocas de globalização, mas como expressão de uma forma nova de produzir industrialmente utensílios, que passa a se basear também na publicidade.

É importante esclarecer que o design do século XX se apoia na substituição mais rápida dos produtos a fim de suportar um mercado opressivo e, em meio a essa complexidade busca reinventar seu valor em detrimento do desenho industrial que se traduz pela produção criativa menos comprometida pelo capitalismo que marcou a industrialização do século XIX, onde os parâmetros de durabilidade, qualidade eram outros e não havia mercados formados de forma tão ostensiva como se tem hoje.

O reconhecimento do substantivo design mostra os obstáculos superados para que ele viesse a se tornar um vocábulo presente no dicionário de língua portuguesa, por exemplo, além do aspecto produtivo em si que demanda do design uma versatilidade maior na sociedade pós-industrial.

Aceitioda vale reforçar o caráter técnico marcante quando se fala em desenho industrial. A separação entre indústria e criação artística passa a ser mais marcante a partir da metade do século XIX e entra no século $X X$ fortemente delineada, embora não tenham faltado tentativas de atos interdisciplinares que uniam ambas as áreas. A questão da divisão destas duas áreas sempre foi motivo de discussão e até hoje não se encontra completamente resolvida. Essa irresolução se desdobra pela história que retrata variações no entendimento de design e arte.

Ars do latim equivale a techné (FLUSSER, 2007, p. 183). Na antiguidade arte e design se equivaliam em certo sentido. Os dois termos se traduzem na noção de manobra, agilidade que dá origem ao ato e ao produto final deste ato. O produto final que justifica o ato artístico é a obra de arte. E o objeto é o resultado do ato criativo e processual do design.

Outro termo da antiguidade relaciona artifex a impostor. O artista seria então um prestidigitador que se utilizaria de artifícios para manipular. É ele quem tem poder - Kunst em alemão deriva do verbo poder - no sentido de poder realizar algo (FLUSSER, 2007, p. 183). Esse sentido de manipular um produto para lhe dar determinada aparência, além do sentido de criar, transformar, é costumeiramente associado ao design por meio do styling. $\mathrm{Na}$ afirmação de Flusser percebe-se que designer e artista nem sempre foram indivíduos com 
características tão diferentes em seus trabalhos.

O êxito almejado tanto pelo artista quanto pelo designer em seus trabalhos, embora com enfoques distintos, deriva do uso de dispositivos, como materiais e em alguns casos máquinas e tecnologias, mais complexos. O principal motor transformador desses dispositivos é a própria subjetividade do designer ou artista que, no fim das contas, é quem revela a essência desse esforço.

Essa subjetividade é expressa na arte por meio do objeto em quantidade mínima e de valor máximo (ARGAN, 2005, p. 252). O valor do objeto artístico está diretamente ligado a escassez e refinamento.

Esses preceitos também se desdobram no design contemporâneo. A cadeira Lockheed Lounge de Marc Newson atingiu status de obra de arte ao ser leiloada com auxílio de Larry Gagosian, que fez as vezes de seu marchand, por quase um milhão de dólares.

Ela surgiu despretensiosa, em uma garagem australiana da década de oitenta, quase na contramão do sonho de consumo, única como uma obra de arte e dessa maneira foi comercializada. A única diferença é que não se tratava de uma obra de arte - pelo menos no conceito arganiano que exclui a questão da funcionalidade recorrente no design.

A referida cadeira era a primeira de uma série de dez, o mock up. Portanto, no mundo da arte tornou-se mais valiosa por ser única. Única no momento do nascimento de uma forma de pensar design que era contemplada por Newson. Essa forma de pensar design não dizia respeito à produção industrial de forma direta. E foi dessa forma que a Lockheed Lounge foi leiloada, como a "prova do artista" um conceito então desconhecido para o design.

Essa transubstanciação de artigo de design em objeto de arte permite uma afirmação audaciosa que demanda um exame mais minucioso. Percebe-se aqui uma confluência entre arte e design atuais: o fim último de seus produtos é a venda.

O conceito de ready made', ainda em seu contexto original, ilustra o pensamento de Duchamp que, dotado de ceticismo e ironia, vê o desenvolvimento industrial dos primórdios do período moderno como uma fantasia humana e não como uma revolução industrial que modificou o mundo (ARGAN, 2005, p. 439).

1 O ready made consiste em separar o objeto de seu contexto, o que alterava seu significado, "retificando-o". (CABANNE, 2000). Marcel Duchamp usava em suas obras objetos industrializados para constituir o seu discurso, daí o nome ready made. 
Esse traço marcante na obra do artista coincidiu com uma perda de significado do desenvolvimento moderno que só se intensificou em detrimento das desigualdades causadas pelo desenvolvimento acelerado do capitalismo. Por isso, atualmente o ready made ainda é um conceito tão atual.

A obra de arte em seu conceito moderno, arganiano, inicialmente nunca seria achada em série para consumo. Foi Marcel Duchamp que a partir da criação do ready made se tornou inesquecível e quase intocável. Atualmente tem-se a impressão de que o conceito de ready made nunca poderá ser contrariado, pois seu sentido se intensifica diante da sociedade de consumo, alinhando-se de maneira cada vez mais fina ao capitalismo tardio.

O objeto duchampiano está tão alinhado ao capitalismo tardio quanto o design de Marc Newson, Philippe Starck, Ron Arad, Alessandro Mendini, Gaetano Pesce, Zaha Hadid e Karim Hashid.

Na moda esse "ready made às avessas"que é o produto de design com ares de obra de arte, esse produto-moda feito em "quantidade mínima com valor máximo" se configura na alta costura que se rebate na produção de Paul Poiret, Elsa Schiaparelli, Giorgio Armani, Thierry Mugler, Azzedine Alaïa, Hussein Chalayan e Marc Jacobs. Esses estilistas sempre buscaram unir seu trabalho à arte.

Sua consequente aproximação do campo da arte trouxe uma valorização, quase que por transferência, ao campo do design que permitiu que em alguns momentos do design contemporâneo e da moda moderna e contemporânea o design fosse tratado como obra de arte.

A arte, por sua vez, também acolhe ao funcionamento do design quando permite que seus museus e casas de leilão exibam e vendam produtos de design como no caso de Marc Newson e sua Lockheed Lounge. A arte concorda com certa aproximação do design quando empresta seus conceitos, espaços expositivos e imagens a ele.

Se por um lado a lógica do consumo liberta e faz de designers artistas e vice-versa, por outro ele desvia a atenção do criador - designer ou artista - de seu objetivo inicial de conceber, respectivamente, produtos ou obras de arte. Em alguns casos eles se arriscam quando passam a atender quase que exclusivamente uma demanda de mercado, tentando acompanhá-la freneticamente. Assim atuam como artista e como designer a despeito de suas vocações originais. 
Nesse caso, a porosidade se rebate sobre a moda, o design e a arte e quando se tem esse panorama uma se imiscui à outra. Deve-se ter cuidado enquanto designer com o distanciamento de sua área de origem para migrar para a arte, por exemplo. Isso se estende à moda e à arte. Essa situação pode se complexificar, quando se percebe uma névoa sobre a área de atuação profissional de alguns desses designers, que ora versam como artistas ora como designers de interiores ou arquitetos. Alguns são reconhecidos pela sua área de origem, mas parecem cada vez mais distanciarem-se dela.

Ao longo da história percebe-se que a atuação de designer como artista ou de artista como designer começa quase que ocasionalmente, por se tratar de áreas correlatas. Após um primeiro contato se sucedem outros com campos análogos envolvidos, que em alguns casos dificultam vislumbrar a qual campo de atuação um profissional pertence.

Esse embaçamento ocorre justamente por uma área ser complementar a outra em determinadas situações. Não há interesse aqui em criticar a prática interdisciplinar, uma vez que é reconhecido o benefício de seus atos.

\section{Casos entre moda e arte do século XX e a preocupação interdisciplinar}

Ao mesmo tempo é importante entender que se a união de disciplinas promove inúmeros avanços na forma de fazer, pensar e ver design, ela também complexifica o panorama desta área quando questiona algumas verdades cartesianas.

Embora haja risco de um designer ou um artista se distanciar de sua área em um ato interdisciplinar, esse artigo busca discorrer a respeito de atos conjuntos entre design de moda e arte, entre outras questões, que foram bem sucedidos.

Há alguns casos ao longo da história que ilustram essa situação. Varvara Stiepânova, artista do Construtivismo Russo defendia que a roupa deveria expor a maneira como era costurada e, consequentemente, seu dinamismo. Expor como as peças haviam passado por máquinas de costura, como a máquina reta $^{2}$ por exemplo, lembrava a agilidade moderna. Tanto Varvara Stiepânova quanto Aleksandr Ródtchenko foram capazes de desenvolver tecidos inovadores e designs de roupas. Stiepânova trabalhou na Primeira Fábrica de $\mathrm{O}$

2 A máquina reta é a principal máquina destinada à confecção de peças de roupas, utilizada principalmente em tecido plano. Possui aspecto tracejado. 
Construtivismo que, nesse momento dava muita importância ao processo e a unir arte e vida, disseminou formas geométricas para substituir as tradicionais padronagens florais russas. Futuramente, na década de sessenta, essa estética geometrizante influenciaria a construção de roupas do estilista Pierre Cardin.

Outros casos onde o ofício de estilista se imiscui ao de artista e o de artista ao de estilista são o de Elsa Schiparelli e Salvador Dalí. A designer Elsa Schiaparelli recusou o estilo moderno da década de vinte, do qual Chanel foi expoente, desenvolvendo uma tendência ao surrealismo que a cercou de artistas como Man Ray, Tristan Tzara, Hans Picabia, Jean Cocteau, Salvador Dalí e Meret Oppenheim. Schiaparelli experimentou materiais como celofane, vidro, plástico e náilon de pára-quedas trabalhando os acessórios em excesso (WOLLEN, 1999, p. 14).

Entre seus feitos está o Sapato de Pêlo de Macaco, de 1938, criado sob a influência do surrealismo em seu trabalho, em especial de Salvador Dalí. Trata-se de um sapato com cabelo que confere uma excentricidade artística ao sapato, mesmo se pensado na atualidade.

Dalí também se deixou influenciar pela moda de certa forma. Sua Dinner Jacket, de 1936, retrata a vida boêmia pelo olhar surrealista. Nessa obra ele conta com elementos caros à moda como a lingerie feminina, a camisa, o paletó e a gravata masculinos, que mostram como a relação com Schiaparelli $\mathrm{Na}$ década de cinquenta houve artistas cruzando a barreira entre o avant-garde e a cultura popular (WOLLEN, 1999, p. 15).

Em 1956, em Nova lorque, a artista japonesa Atsuko Tanaka iluminou seu Electric Dress com lâmpadas elétricas coloridas. Era um ato entre uma escultura e uma performance que foi criado sob a forma de um vestido com luzes.

Por último, no fim do século, vale citar o trabalho do grupo Vexed Generation. Suas roupas que mais parecem máscaras de gás que transbordaram sobre o corpo cosmopolita do fim do século XX têm a função de camuflar esse corpo no caos da cidade.

Essas experiências mais politizadas entre arte e moda aconteceram na década de noventa. As criações do grupo Vexed Generation se destacam por apresentar um interesse específico nas questões da cidade que se intensificaram no final do século passado poluição, vigilância, fiscalização e o exercício da autoridade por parte da polícia (EVANS, 1999, p. 99).

Nos quatro casos supracitados a falta de vínculos exclusivos - em um sentido moderno - com a área da moda ou da arte exigem a criação de um contexto específico para a interpretação dessas produções, sejam elas design ou obra de arte. 
Após a década de sessenta com o início do questionamento dos ditames modernos e a proliferação de práticas interdisciplinares concernentes tanto à arte quanto ao design, muito se questionou a respeito dessas obras. Apesar disso a produção hibridizada entre essas áreas só se intensificou.

Ao contrário da cadeira Lockheed Lounge de Marc Newson, que foi concebida em um contexto onde design não era pensado de forma tão próxima à arte, muitos objetos de designers como Philippe Starck ou Gaetano Pesce foram criados sob a égide da simbiose com a arte o quanto isso foi possível. Isso gera um movimento que vai do design para a arte, contrariando a afirmação de Argan (NAVES, 2010, p. XII) de que a única forma válida de relação com a arte é a que sai dela para a sociedade.

O mesmo acontece com a arte de Damien Hirst quando ele cede os direitos de seu trabalho à Levi's, só que alterando o movimento que vai da arte para o design de moda.

Mesmo reconhecendo que se tratam de objetos de design, percebe-se que eles foram projetados de forma a superar o binômio da forma e função moderno. Esse relato é evidenciado também na maneira como os donos desses objetos fazem questão de exibi-los em suas casas e ambientes de trabalho de forma que se assemelhem a obras de arte.

Embora o presente artigo tenha interesse em investigar as relações entre arte e design não cabe aqui categorizar de forma cartesiana o que é arte ou design. O interesse maior recai sobre o processo de gerar híbridos.

\section{O olhar contemporâneo X o olhar moderno}

Há uma espécie de tabu na aceitação, do trabalho do artista como designer e do designer como artista, mesmo que ele seja esporádico. O olhar moderno insiste em uma visão tão arraigada de pertencimento a uma área de atuação estanque, que oscilar entre outras áreas pode implicar em falta grave.

A recorrência do artista como designer e do designer como artista remonta a Antiguidade Clássica a despeito da insistência cartesiana em dividir as áreas do conhecimento de maneira tão definitiva. Talvez a lógica moderna tenha feito erigir uma barreira sólida demais entre essas áreas e agora o pensamento contemporâneo reivindica um amolecimento das fronteiras.

Esse sentimento tem origem no desabono sofrido pelos ideais modernos. 
Segundo Canclini (2008, p. 33),

[...] a ciência e arte que se distanciaram da tutela da religião a partir do Renascimento teriam, supostamente, condições de crescer no sentido de ajudar a ampliar o entendimento do mundo, trazer progresso moral ao mundo e tornar mais justas as instituições e as relações sociais. Mas, ainda segundo o autor, o que se percebe é que foi aberto um abismo entre a moral, a ciência e a arte tornando-as completamente independentes entre si e desconectadas da vida cotidiana.

Esse pensamento se rebate sobre a arte e o design que ao mesmo tempo coincidem e se contradizem. São capazes de estetizar objetos que sensibilizarão as pessoas, em quantidade muito limitada e de modo a serem cultuados, ou de forma que também sejam cultuados, mas incensados pela produção estandardizada que massifica.

Houve fases ou regiões culturais inteiras em que a práxis prevaleceu sobre a teoria e outras em que a teoria predominou sobre a práxis, o que levou a segunda a ser reduzida à operação mecânica que, por sua vez, está sempre aquém de um modelo ideal (ARGAN, 2005, p. 13-14).

Quando se reconhece que a prática era considerada menor se comparada à produção de subjetividade quase que exclusiva à arte, torna-se permitido afirmar que nem sempre o ideal moderno de unir arte e vida foi contemplado.

Criou-se uma mácula no design quando o assunto é valor estético. Parece que esse critério só atende formalmente à arte e, quando associado ao design em termos intelectuais, tende a desvalorizá-lo se não concerne à forma moderna.

O postulado da forma e função de Ulm contaminou tão profundamente o design que ainda hoje muitas escolas o repetem de forma a tentar coibir os futuros profissionais de criarem artigos considerados impróprios à estética do desenho de produto moderno.

Esse racionalismo cindiu de forma profunda qualquer laço entre design e arte. Ao longo do século XIX a divisão entre artes e ofícios que antes era mais tênue se acentua até ser racionalizada em uma forma que pensava ser definitiva.

A certeza moderna começa a dar espaço a outras formas de conceber 
produtos e em meados do século $X X$ as esferas da arte e do design voltam a se fundir, mesmo que timidamente.

Pensar design e arte de forma completamente separada passa a ser uma atitude questionada no final do século passado. No início do século XXI a mistura entre diferentes áreas e disciplinas volta a parecer mais natural - em um contexto onde o design assume o papel de um dos grandes impulsionadores do consumo por meio de uma exacerbação do styling que responde prontamente aos anseios do capitalismo tardio - e se intensifica.

O saca-rolhas Anna G. de Alessandro Mendini é um bom exemplo. Até 2005, só existia o original, da marca Alessi. Pouco tempo depois, já era possível encontrar sua cópia no mercado popular. Essa difusão em termos visuais engendra novas formas de pensar, de conceber e usar design. Embora se trate de um saca-rolhas, não é a questão funcional a que mais interessa. O modo de pensar, conceber e usar design, em um sentido mais amplo, passa a ser preponderante sobre a função no final do século $X X$, o que leva a aproximar o design da arte.

Philippe Starck e o Juicy Salif denotam a forma contemporânea de pensar design que prevê o styling como pressuposto básico e não como auxiliar. Esse desejo de possuir o belo e usá-lo no dia-a-dia mostrou-se imperativo na sociedade capitalista recente.

Houve intensificação do consumo de design no que diz respeito à objetos criados por Mendini e Starck. Suas criações podem ser vistas em muitas casas aparecendo entre os utensílios domésticos orgulhosos de suas formas. Não basta usá-las, elas têm que estar aparentes.

Pode-se dizer ainda que o design foi massificado, como no caso do saca-rolhas de Mendini, à medida que se caminha pelas ruas entre lojas de utensílios domésticos populares. O Anna G. caiu no gosto popular e foi copiado, desdobrado e reproduzido à exaustão para saciar o gosto de um mercado mais amplo e massificado que, assim como as camadas mais elitizadas da sociedade, busca ser único ante a produção em massa.

A aparência das coisas é, para o design, uma consequência das condições de sua produção (FORTY, 2007, p. 12). Assim, os objetos do design, sejam eles de moda, de produto, gráfico ou de embalagem sofrerão os efeitos do l'air du temps ${ }^{3}$. De acordo com mudanças culturais ligadas a um determinado período eles passarão por mudanças estéticas e funcionais. Essa difusão afetará também o entendimento que se tem do que é artesanato ou design em cada período. 
Assim como as várias formas de design, a arte também mantém a convicção no l'air du temps, uma vez que sua história oscilou entre períodos onde houve o predomínio da práxis ou da teoria, por exemplo. Em dado momento, a arte figurou como objeto, sendo modelo para outras atividades (NAVES, 2010, p. XXI) como no caso do artesanato. A obra de arte deve ser apreciada no contexto do seu tempo e circunstancialidade (JANSON, 1992, p. 9), por isso não é possível separá-la da conjuntura em que ocorre e mesmo da vida cotidiana.

Existe atualmente uma contiguidade entre arte e design cada vez mais explícita. O consumo em massa de produtos industrializados desenhados por grandes designers gráficos, de produto e de moda ou de artistas faz com que a linha que separa o design da arte obnubile-se em direção a um caminho que leva a forma de conceber design a se aproximar muito dos processos inerentes à arte.

Os produtos de Mendini e Starck levam ao ápice o consumo do capital cultural, que se desdobra em produtos como os jeans e camisetas estampadas de Damien Hirst para a Levi's, ou as sandálias de Zaha Hadid, e mais recentemente Karl Lagerfeld, para a Melissa.

Um indivíduo pode não ter acesso a uma grande arquiteta para projetar sua casa ou a vestir uma roupa de alta-costura, mas tem possibilidade de contato com estes trabalhos adquirindo a sandália projetada pelos indivíduos que trabalham nesses segmentos. Esse mesmo consumidor talvez não seja um comprador de arte, mas consome a seu modo a estética da Damien Hirst, inserindo-a no seu cotidiano por meio do seu jeans e camiseta. O objeto mais ordinário se transforma em uma experiência estética da cultura popular.

Alessandro Mendini, Philip Starck, Damien Hirst ou Zaha Hadid equiparam-se na materialização de uma assinatura prestigiosa em campos interdisciplinares. A partir daí percebe-se o interesse das pessoas em design e arte, o que reforça a ideia de que os dois campos não tenham que atuar obrigatoriamente desmembrados para manterem sua identidade e individuação.

Sempre foi creditado ao trabalho criativo do artista a capacidade de renovar a experiência da realidade estabelecendo uma relação entre a arte e a sociedade que sai da primeira para segunda, nunca ao contrário (NAVES, 2010, p. XII). Essa relação, se pensada entre design e sociedade, pode ser pensada ao contrário da lógica da arte moderna. Fenômenos sociais podem tomar forma e trazer renovação e experiência da sociedade para o design.

A relação que parte da arte para a sociedade se concretiza mesmo quando o design é privilegiado. Supondo a arte como o motivador de um gesto criativo 
no design, essa lógica ainda é respeitada. Mas o que dizer quando é a arte quem empresta do design fragmentos para sua criação?

Quando há troca entre design e arte, configura-se também o movimento que envolve a sociedade. Abre-se a possibilidade de, por meio do design, o caminho proposto por Argan se inverter e a relação ir da sociedade para a arte, ao contrário do que ele afirmava. Uma vez que essa possibilidade existe no campo do design, ela se estende à arte quando as duas áreas trocam.

As experiências híbridas se alastram para além da arte e do design chegando à moda. Essa arguição entende moda e design como áreas correlatas.

Dada a capacidade e necessidade de mudança da moda, posto que o que tem valor máximo para a moda é a mudança, os processos de hibridação (CANCLINI, 2008, p. XXIII) ou de atos interdisciplinares atendem a essa demanda em um mundo onde o capitalismo tardio dotou a sociedade de acesso quase irrestrito à informação. Foi preciso então encontrar novas formas de mudar para saciar a dinâmica da moda.

A possibilidade do trabalho conjunto entre áreas distintas, moda, design ou arte, ganha fôlego por aumentar o espaço de renovação que a moda, ensejada pelo capitalismo que intensifica as relações de consumo, demanda.

O sociólogo Gilles Lipovetsky (1989, p. 107) nomeia o período na moda de 1850 a 1960 de "moda de cem anos". Esse século representou uma nova fase da história da moda. A emergência de um sistema de renovação constante da moda desse período não compreendeu qualquer ruptura com o passado moderno. A burocracia na produção de roupas de moda orientada por criadores e estilistas, a lógica da produção em série, as coleções criadas a cada estação, os desfiles e a publicidade de moda serão alterados pelo redescobrimento do sistema de moda, posterior a década de sessenta.

A ideia de moda no sentido individual e social mudou junto com os gostos e os comportamentos dos sexos de uma nova classe de jovens: os baby-boomers. A avidez pelo consumo aumenta à medida que aumenta o individualismo. Essa fase da moda está diretamente ligada à sua fase anterior, a da moda moderna, que tinha seu ritmo ditado pela alta-costura. Nesse sentido, esse último momento da moda, a partir da década de sessenta, é uma extensão potencializada dos preceitos modernos da moda ligados à sua estética burocratizada por protocolos de difusão de tendências, de produção de peças de roupas, mas que agora tem sua faceta individualizadora e democrática.

É mais simples entender agora porque a moda não é somente a expressão 
da cultura do consumo ou da distinção de classes. Ela também está ligada a ideia de prestígio que flerta com todos os extratos sociais (STERN, 2004, p. 2), para além de aspectos técnicos e outros aspectos que a ligam aos fenômenos sociais.

Quando a moda é pensada como um fenômeno socialmente amplo, se estendendo a outros sistemas, ela pode ser pensada como parte integrante do cenário da arte. Ela exibe o entrelaçamento indissolúvel das esferas econômica, social, cultural, organizacional, técnica e estética. Isso quer dizer que, embora a moda esteja ligada ao belo, ao luxo e ao glamour que aferem a ela um tom de futilidade, o campo se revela como uma zona de manifestação visual de atributos que vão além da estética (SANTAELLA, 2004, p. 115).

O prestígio a que Stern se refere é outro fator que equipara a moda à arte no tocante à exclusividade, embora se saiba que a moda atual atinja muitas camadas, entre elas a popular, o que quase nunca acontece na arte.

\section{CONSIDERACÕES FINAIS}

Atualmente, a moda se encontra em sua forma mais democrática e está disponível para quase todos, independentemente de seus gostos e classe social, e diz respeito a uma individualidade de massa, onde é possível acreditar ser único, mesmo que o objeto escolhido seja produzido em massa. É um design igual para um grande número de pessoas que adquire esses produtos, mas que ao mesmo tempo emana algo de individual para quem os utiliza (SUDJIC, 2010, p. 14).

No livro Para uma crítica da economia política do signo, Jean Baudrillard (1972, p. 88) enfatiza que a moda é um dos fenômenos mais inexplicáveis, pela característica de inovar signos, de produzir significados aparentemente arbitrários e constantes, pelo mistério lógico de seu ciclo, que são, com efeito, parte de sua essência.

Essa singularidade da moda como fenômeno difícil de entender culmina no seu encontro com a arte. Sempre renovando seu ciclo e o mistério que o mantém, a lógica desse ciclo de mudanças constantes acaba por se inverter quando a moda busca a arte para se reinventar. Um dos estratagemas da moda para provocar mudança, e manter assim sua sazonalidade, é transgredir. A moda segue a lógica do avant-garde, contrariando sua essência comercial, quando procura na arte o que pode modificá-la. A arte moderna que tem caráter raro, 
incomparável e excepcional empresta seu elã à moda que se pretende única até a próxima mudança, pois a mudança não prescinde mais a passagem de uma estação para outra quando se fala em moda.

Ainda no que se refere à vestimenta, percebe-se que no mundo ocidental a roupa sempre superou a funcionalidade; desde seus primórdios já possuía caráter mágico, daí o vestuário satisfazer um desejo de representação. É a roupa que vai inspirar medo ou autoridade, distinção por meio do traje do chefe ou do uniforme do policial ou da toga do juiz de direito (BOUCHER, 2010, p. 13-14).

Em vários estágios de desenvolvimento, o homem se viu obrigado a operar mudanças em suas roupas, o que foi exigido para sua adaptação aos progressos que o cercavam. O estudo histórico do vestuário depende de três fases em que se empenhou uma sucessão de predominâncias, entre elas: influências religiosas e místicas, esforços de libertação espiritual e social e concentrações de interesses econômicos (BOUCHER, 2010, p. 17), que são períodos que por vezes coincidem com os períodos da história da arte.

A arte produzida na Idade Média quase sempre esteve subordinada aos desejos da Igreja. A arte supera a vontade da Igreja no Renascimento quando os indivíduos se tornam mais participativos no convívio social, quando a política se desenvolve de maneira mais pungente, quando o comércio permite a ascensão social e o ideal de individualismo começa a se formar, mesmo que no contato do indivíduo com Deus como ser único. A Igreja não é mais a única a intermediar contato com Deus.

Essa superação das dificuldades inerentes a cada período, tanto pela moda quanto pela arte, mostra até onde a afinidade destas áreas da produção visual pode ir. Alguns obstáculos se mostraram mais ou menos os mesmos tanto para a moda quanto para a arte, mas cada uma buscou sua própria forma de se expressar e se impor, principalmente a partir do século XIX, quando mudanças sociais, políticas e econômicas começam a ocorrer de forma mais frequente.

De maneira geral, a partir desse período a arte se resguardou cada vez mais ao status de objeto único enquanto a moda buscou espaço na produção industrial. Mas esse antagonismo não pode cercear a criação de novos vínculos entre ambas disciplinas. Embora sejam distintas elas podem agir de maneira conjunta de forma frutífera como mostram os casos expostos. Zygmunt Bauman faz tomar consciência da

[...] fluidez como metáfora da contemporaneidade, de uma nova forma de se apresentar na história da modernidade. Defende, em outra metáfora, que os sólidos modernos 
estão se desintegrando. A separação total das áreas deixa de fazer sentido em um momento cada vez mais fronteiriço (BAUMAN, 2001, p. 1).

É possível estabelecer relações entre as modas e as escolas artísticas de cada período, ou mostrar o valor dado pela arte à moda na pintura, por exemplo, por meio dos panejamentos, mas o que se pretende aqui, sobretudo é mais evidente embora mais complexo.

Não se busca aqui estabelecer uma relação de valores entre as duas disciplinas, moda e arte. $O$ interesse maior se concentra em superar as divisões cartesianas impostas pela modernidade às disciplinas, mantendo as características intrínsecas a cada uma delas, mas ao mesmo tempo incentivando a prática interdisciplinar, híbrida.

É importante aceitar atos híbridos e reconhecer seu valor, assim como a operação independente dessas áreas separadas pelo cartesianismo. É fundamental que os processos híbridos sejam tão naturais quanto os não híbridos.

Respeitando moda e arte como objetos distintos é possível reconhecer casos, como os já citados nesse texto, em que a alternância entre um campo e outro opere positivamente para o engrandecimento cultural e social que são papéis fundamentais, tanto da arte quanto do design. 


\section{REFERÊNCIAS}

ARGAN, G. C. Arte Moderna. São Paulo: Companhia das Letras, 1992.

História da arte como história da cidade. São Paulo: Martins

Fontes, 2005.

BAUDRILLARD, J. Para uma crítica da economia política do signo. Lisboa:

Ed. 70, 1972.

BAUMAN, Z. Modernidade Líquida. Rio de Janeiro: Jorge Zahar, 2001.

BOUCHER, F. História do vestuário no ocidente: das origens aos nossos dias. São Paulo: Cosac Naify, 2010.

CABANNE, P. Marcel Duchamp: o engenheiro do tempo perdido. São Paulo: Perspectiva, 2000.

CALDAS, Dário. Observatório de sinais: teoria e prática da pesquisa de tendências. Rio de Janeiro: Senac Rio, 2004.

CANCLINI, N. G. Culturas híbridas: estratégias para entrar e sair da modernidade. São Paulo: Universidade de São Paulo, 2008.

EVANS, C. Mutability and modernity: the 1990's. In: WOLLEN, P. Addressing the century: 100 years of art and fashion. Califórnia: University of California Press, 1999.

FERRARA, Lucrécia D'Alessio. Desenho industrial: da transmissão à tradução. Pos, São Paulo, v.18 n.29, 2011.

FLUSSER, V. O mundo codificado: por uma filosofia do design e da comunicação. São Paulo: Cosac Naify, 2007.

FORTY, A. Objeto de desejo: design e sociedade desde 1750. São Paulo: Cosac Naify, 2007.

JANSON, H. W. História da arte. São Paulo: Martins Fontes, 1992.

LIPOVESTSKY, G. 0 império do efêmero: a moda e seu destino nas sociedades modernas. São Paulo: Companhia da Letras, 1989.

NAVES, R. Prefácio. In: ARGAN, G. C. Arte moderna. São Paulo: Cia. das Letras, 2010. p. XI-XXIV. 
SANTAELLA, L. Corpo e comunicação: sintoma da cultura. São Paulo: Paulus, 2004.

STERN, R. Against fashion: clothing as art, 1850-1930. Massachusetts: MIT, 2004.

SUDJIC, D. A linguagem das coisas. São Paulo: Intrínseca, 2010.

TANAKA, Atsuko. The Art of Connecting. Artdesigncafé, 2011. Disponível em: <http://www.artdesigncafe.com/atsuko-tanakaartist-2011>. Acesso em: 10 fev. 2013.

VEXED GENERATION. Vexed Products: Puma Vexed. 2012. Disponível em: <http://muneebabutt.wordpress.com/2012/ 02/06/vexedgeneration/>. Acesso em: 10 jul. 2013.

WOLLEN, P. Addressing the Century: 100 years of art and fashion. Califórnia: University of California Press, 1999. 


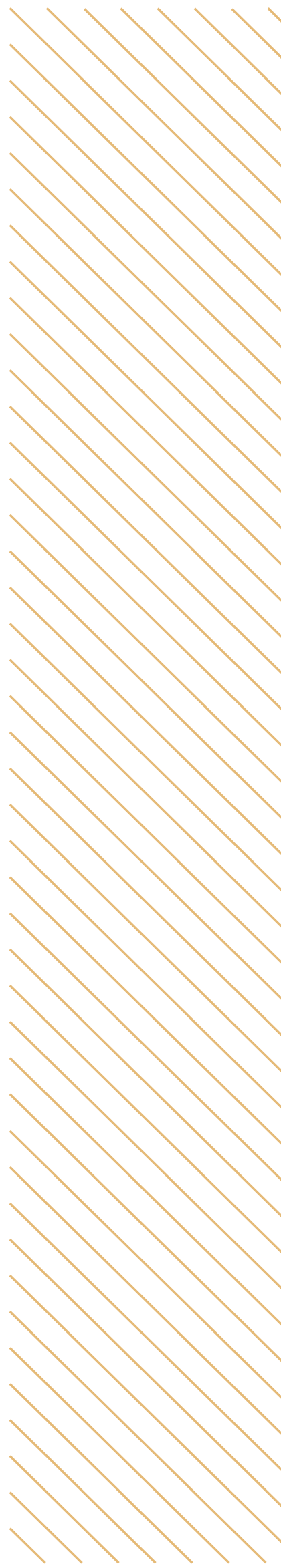

